\title{
Пути сохранения и использования генофондных пород и популяций сельскохозяйственных птиц на примере русской белой породы кур
}

Федорова Е.С., кандидат биологических наук, старший научный сотрудник отдела генетики, разведения и сохранения генетических ресурсов сельскохозяйственных птиц

Станишевская О.И., доктор биологических наук, зав. отделом генетики, разведения и сохранения генетических ресурсов сельскохозяйственных птиц Всероссийский научно-исследовательский институт генетики и разведения сельскохозяйственных животных (ВНИИГРЖ) филиал ФГБНУ «Федеральный научный центр животноводства - ВИЖ имени академика Л.К. Эрнста»

Аннотация: Статья посвящена проблеме сохранения и использования генофондных пород сельскохозяйственной птицы на примере популяции русских белых кур, которая может быть использована при создании специализированных популяций кур для целей биопромышленности. Это особенно актуально 6 настоящее бремя, не только $\theta$ сөязи с необходимостью решения задачи импортозамещения, но и из-за сложной эпизоотической обстанобкой 6 миробом птицебодстве, а также напряженной ситуации, с6язанной с пандемией нового вида коронавируса. Предстаблены данные о результатах отбора птицы по छыходу аллантоисно-амниотической жидкости (ААЖ) у 12,5-суточных эмбрионов за 5 поколений; критерий отбора-не менее 0,200 мл/г массы яйца и не менее 10 мл на эмбрион. Увеличение быхода бакиинного сырья по популяции 6 целом также было достигнуто с помощью отбора кур по яйценоскости и массе яиц. Селекционная работа с популяцией прибела к повышению яйценоскости на 15\%, массы яиц-на 10\%. Объем ААЖ увеличился на 14\% 6 абсолютной величине (мл) и на 8\% - 6 относительной; биологическая активность Вируса болезни Ньюкасла - на 11,5\%. Частота Встречаемости кур с Высоким Выходом ААЖ уВеличилась $\theta$ среднем на 25,2\%. Результаты вирусологических исследобаний эмбрионов кур популяции русская белая также позволяют рекомендовать их для использования в производстве ряда вирусных вакцин и диагностикумов.

Ключебые слова: куры, русская белая порода, вакцинное сырье, селекция, экстраэмбриональная (аллантоисно-амниотическая) жидкость, биологическая активность вируса.

Введение. В настоящее время в России осталось лишь два коллекционария, занимающихся сохранением редких и исчезающих пород кур: на базе ВНИТИП (Московская область) и ВНИИГРЖ (Санкт-Петербург). С одной стороны, сохранение генетических ресурсов, коими являются локальные породы - это общемировая проблема, поскольку сужение генетического разнообразия характерно не только для малочисленных пород птиц, но также и для промышленных линий [1]; так, по данным ФАО, по состоянию на 2015 г. из 1729 известных пород кур только 212 не имеют статуса риска исчезновения. Исчезновение генофондных пород влечет за собой снижение генетической изменчивости и генетического разнообразия сельскохозяйственной птицы за счет утраты ценных специфических генов и их сочетаний, определяющих высокую жизнеспособность и 
резистентность птицы к различным заболеваниям, повышенную питательную ценность продукции (яиц, мяса), неприхотливость К условиям содержания и кормления, устойчивость к тем экстремальным климатическим условиям, в которых формировались данные породы [2].

С другой стороны, наиважнейшим условием сохранения любой генофондной породы является возможность или перспектива использования ее ценных признаков. Это может быть либо получение продукции птицеводства с повышенными качественными характеристиками или питательной ценностью (яйцо, мясо, перопуховое сырье), либо использование в качестве источника определенных генов для целей генной инженерии, или же как продуцента сырья для биопромышленности, в т.ч. для производства вакцин и диагностикумов [3].

Именно такое решение избрали при работе с популяцией русских белых кур из «Генетической коллекции редких и исчезающих пород кур» ВНИИГРЖ. Эта популяция была создана А. Н. Соколовой [4] в 60-70-е годы прошлого века путем отбора на резистентность $\mathrm{K}$ пониженным температурам выращивания в первые дни жизни цыплят с последующим содержанием взрослой птицы в зимний период при температуре ниже $0^{\circ} \mathrm{C}$, но при сохранении яичной продуктивности на максимально высоком уровне. В результате селекции в условиях сублетальных пониженных температур появились генотипы, отличающиеся не только терморезистентностью молодняка, но и повышенной устойчивостью к ряду неопластических заболеваний, таких как болезнь Марека, лейкоз, карциномы [4].

Мы считаем, что использование кур русской белой породы в качестве продуцента сырья для целей биопромышленности имеет большие перспективы, поскольку эпидемическая и эпизоотическая обстановка в мире усложняется с каждым годом, и, как следствие, увеличивается потребность в вакцинах, как для животных и птицы, так и для человека. Здесь необходимо отметить, что, несмотря на широкое использование культурального метода, использование развивающихся эмбрионов кур (РЭК) является незаменимым для производства целого ряда вакцин [5].

Наилучшим сырьем для производства вакцин являются SPF-яйца (свободные от специфических патогенов). Производство SPF-яиц экономически является очень затратным, поскольку они производятся в условиях строгой изоляции и не содержат антигенов и антител против агентов, список которых представлен в Европейской фармакопее. Особенностью SPF-яиц является полное отсутствие вакцинаций птицы [6,7]. Для изготовления вакцин могут быть использованы также так называемые жчистые яйца», особенностью которых является отсут-ствие в них специфических антигенов и антител благодаря «щадящей» схеме вакцинации птицы или отсутствию вакцинации против определенных заболеваний. Поскольку в нашей стране нет специализированных популяций, отселекционированных для целей биопромышленности, для производства вирусных вакцин и диагностикумов используются яйца кур обычных промышленных кроссов, подвергающихся жесткой схеме вакцинации (что неблагоприятно сказывается на качестве вакцин), или закупаемые за рубежом SPF-яйца (что очень дорого, и показатели оплодотворенности этих яиц недостаточно высоки вследствие значительной степени инбридинга в стадах кур, от которых их получают).

Кроме того, взятый Россией курс на импортозамещение подразумевает также снижение зависимости от иностранных поставок и в сфере фармакологии. Таким образом, давно назрела необходимость разработки селекционных приемов оценки и отбора кур для целей российской биопромышленности, а также создание отечественных специализированных популяций кур для производства вирусных вакцин и диагностикумов.

Материал и методика исследований. Исследования 
проводились на популяции русских белых кур, разводимой в ЦКП «Генетическая коллекция редких и исчезающих пород кур» ВНИИГРЖ и изначально селекционируемой на устойчивость к пониженным температурам выращивания молодняка в раннем возрасте и неопластическим заболеваниям [4]. Птица экспериментальной популяции содержалась в индивидуальных клетках при искусственном осеменении и принятой в хозяйстве технологии кормления и содержания. Массу яиц и эмбрионов определяли с точностью до 0,1 г на весах AND HL-400. Абсолютный обьем аллантоисноамниотической (экстраэм6риональной) жидкости (ААЖ) определяли у 12,5-суточных эмбрионов (возраст, в котором объем этой жидкости достигает максимальных значений) с помощью мерного цилиндра с точностью до 0,1 мл; относительный - в расчете на 1 г массы яйца. Полученные данные обрабатывали с помощью программы для статистического анализа данных Microsoft Excel и Statistica 10.0 .

Основным критерием отбора при проведении селекции на протяжении 5 поколений являлся средний выход ААЖ от 3-5 шт. 12,5-суточных эмбрионов от каждой курицы. Для воспроизводства следующего поколения использовались только куры, эмбрионы которых давали не менее 0,200 мл ААЖ/г массы яйца и не менее
10 мл АЖ на эмбрион; петухи - от матерей и имеющие сестер с такими же показателями выхода ААЖ их эмбрионов [8]. Уровень отбора находился в пределах 24-26\% по курам и 5-6\% по петухам, среднее поголовье кур и петухов в гнездах после отбора составляло 420 и 60 голов соответственно.

Титр вакцинного вируса $\mathrm{k}$ болезни Ньюкасла (штамм «ЛаСота»), реовирусной инфекции (штамм «1 133») и инфекционному 6ронхиту кур (штамм «4/91») в $F_{0}$ и $F_{5}$ определяли во Всероссийском научно-исследовательском ветеринарном институте птицеводства (ВНИВИП) на РЭК русской белой породы кур селекции ВНИИГРЖ методом титрования вируссодержащей жидкости. Титр вируса определяли по методу Кербера в модификации И.П. Ашмарина. Возраст кур при оценке составил 40 недель.

Результаты исследований и их обсуждение. В результате длительной селекции русских белых кур в условиях сублетальных пониженных температур появились не только генотипы, отличающиеся терморезистентностью молодняка и повышенной устойчивостью к ряду неопластических заболеваний, но также было установлено, что в сравнении с другими генофондными породами эмбрионы русских белых кур обладают более высоким выходом AAЖ и титром вакцинного вируса в ней [9].
Поэтому именно с курами популяции русская белая была начата работа по созданию специализированной популяции для целей биопромышленности. Селекционная работа, направленная на увеличение выхода ААЖ у эмбрионов, велась как с петухами, так и с курами, поскольку в результате анализа полученных данных по выходу ААЖ с учетом генеалогии было установлено, что основополагающую роль в передаче такого признака, как уровень выхода ААЖ эмбрионов, играет материнский организм. Расчетный коэффициент наследуемости относительного выхода ААЖ (мл/г) по матерям составил 0,25, в то время как по отцам его значение находилось на уровне 0,19 [810].

В $F_{0}$ было укомплектовано 12 гнезд, в ходе дальнейшей селекционной работы выделено 15 лучших по показателю выхода ААЖ семейств. Наибольшему нажиму отбора по показателю выхода ААЖ подверглись петухи, которые оценивались по продуктивности их матерей и сестер, а также по частоте встречаемости своих дочерей с высоким выходом ААЖ ихэмбрионов.

В селекционной работе для дальнейшего воспроизводства использовались только те куры, эмбрионы которых давали не менее 0,200 мл/г массы яйца и не менее 10 мл ААЖ на эмбрион; петухи - имеющие матерей и сес- 
тер с такими же показателями выхода ААЖ их эмбрионов. Несмотря на то, что отбор птицы по показателю повышенной резистентности к заболеваниям сопряжен с рядом трудностей, такими, как низкая наследуемость данного признака, антагонистичность его с показателями продуктивности, а также сложность его оценки, в течение 5 лет в популяции русских белых кур была проведена успешная селекционная работа на увеличение уровня выхода ААЖ (абсолютного и относительного) у 12,5-суточных эмбрионов. Отбор по данному показателю позволил увеличить за 5 поколений число кур с выходом жидкости 0,200 мл/г массы яйца и выше. При сравнении по этому признаку петухов, оцененных в $F_{0}$, c их потомками в $\mathrm{F}_{4}$ установлено, что частота встречаемости кур-дочерей с высоким выходом ААЖ практически во всех гнездах увеличилась в среднем на 25,2\%. Это доказывает, что селекция кур на увеличение выхода вакцинного сырья от их эмбрионов (ААЖ) достаточно эффективна. Положительный эффект достигается как за счет увеличения выхода ААЖ от самого эмбриона, так и за счет увеличения общего числа эмбрионов из расчета на курицу в связи с повышением яичной продуктивности кур-матерей (яйценоскости и массы яйца, которая также позволяет увеличить получаемый объем вакцинного сырья). Интенсивная селекционная работа с популяцией кур русская белая привела к повышению яйценоскости за 5 поколений отбора на 15\%, массы яиц - на 10\%. Объем ААЖ увеличился на 14\% в абсолютной величине (мл) и на 8\% - в относительной (мл/г массы яйца) $(P<0,001)$.

Вирусологические исследования РЭК популяции русская белая показали, что они обладают не только высоким выходом ААЖ, но также значительным уровнем ее биологической активности (содержанием в единице объема доз вируса, каждая из которых способна вызвать патолого-анатомические изменения у $50 \%$ зараженных эмбрионов - ЭИД 50 ). Так, в $F_{0}$ биологическая активность вируса болезни Ньюкасла находилась на уровне 9,3 Ig эИД ${ }_{50} / \mathrm{cm}^{3}$, что уже было на $3 \%$ выше в сравнении с леггорнами родительского стада кросса «Lohmann LSL» [9]. В результате селекционной работы на увеличение выхода вакцинного сырья в $\mathrm{F}_{5}$ биологическая активность вируса повысилась на $11,5 \%$ и составила $10,51 \mathrm{lg}$ ЭИД $_{50} / \mathrm{cm}^{3}$.

Наибольший ущерб промышленному птицеводству приносят 2 основные группы инфекционных заболеваний вирусной этиологии. Первая группа - карантинные заболевания, к которым относятся вирусная анемия, оспа и лейкоз. Следует отметить, что попытки иммунизации птицы против вируса лейкоза пока безуспешны, даже несмотря на образование вируснейтрализующих антител в крови больных кур. В промышленном птицеводстве нет ни одной породы птицы, устойчивой к этому заболеванию. В результате селекции кур в условиях пониженных температур и отбору на резистентность к неопластическим заболеваниям куры русской белой породы приобрели устойчивость к лейкозу птиц, что было подтверждено лабораторными исследованиями [4]. Однако на протяжении ряда лет селекционная работа с птицей по этому признаку не проводилась, поэтому для выявления генотипов, сохранивших резистентность к данному заболеванию, необходимо проведение дополнительных исследований.

Вторая группа - это высококонтагиозные заболевания, В т.ч. вызывающие поражение дыхательной системы птицы: болезнь Ньюкасла, грипп птиц, болезнь Гамборо, инфекционный бронхит кур, синдром снижения яйценоскости, а также реовирусная инфекция. В случае заражения болезнью Ньюкасла смертность молодняка может достигать 100\%. Реовирус птиц вызывает заболевания респираторного и кишечного трактов, а также скелета, нанося значительный ущерб промышленному птицеводству. В случае С инфекционным бронхитом, возбудителем которого являются штаммы коронавируса, ситуация 
еще более напряженная вследствие появления новых вариантов вируса с низким уровнем родства К традиционным вакцинным штаммам. При производстве вакцин для культивации вируса инфекционного бронхита наиболее эффективной системой являются РЭК. Культивировать вирус в культуре клеток сложно, для начала его необходимо адаптировать $\mathrm{K}$ РЭК, прежде чем он приобретет способность размножаться в первичной культуре клеток [5]. Возможно, что РЭК также могут быть востребованы для изготовления вакцины от другой коронавирусной инфекции, поражающей не птицу, а человека - COVID-19.

По результатам вирусологических исследований установлено, что РЭК популяции русская белая превосходят эмбрионы от несушек промышленных линий по биологической активности получаемого от них вирусосодержащего материала (ААЖ), идущего на изготовление вакцин. Так, единица объема (см $\left.{ }^{3}\right)$ ААЖ эмбрионов кур породы русская белая содержала в 10,2-25,7 раза больше доз вируса (ЭИД 50 ) болезни Ньюкасла и в 1,3-4,0 раза больше - вируса инфекционного бронхита кур (табл. 1). Уровень биологической активности вируса реовирусной инфекции в эмбрионах кур популяции русская белая селекции ВНИИГРЖ также позволяет рекомендовать их для производства как живых, так и инакти-

Таблица 1. Результапы вирусологических исследований по накоплению и определению биологической активности вирусов болезни Ньюкасла, инфекционного бронхита и реовирусной инфекции в развивающихся змбрионах русских белых кур в сравнительном аспекте

(по данным ВНИВиП)

\begin{tabular}{|c|c|c|c|}
\hline \multirow[t]{2}{*}{ Заболевание } & \multicolumn{3}{|c|}{ Бмологическая активность вируса, lg ЭИД50/см³ } \\
\hline & $\begin{array}{c}\text { Достатонная } \\
\text { биологическая } \\
\text { активность } \\
\text { вирусосодержащего } \\
\text { материала, идущего на } \\
\text { составление серии вакцины }\end{array}$ & $\begin{array}{c}\text { Промышленная } \\
\text { птица }\end{array}$ & $\begin{array}{l}\text { Русская } \\
\text { белая }\end{array}$ \\
\hline \multicolumn{4}{|l|}{ әлезнь Ньюкасла } \\
\hline Ітамм */а-Сотаж) & 10,3 & $9,1-9,5$ & $10,51 \pm 0,17$ \\
\hline \multicolumn{4}{|l|}{ Анфекционный } \\
\hline (штамм «4/91») & 7,2 & $7,0-7,5$ & $7,21 \pm 0,15$ \\
\hline Реовирусная & 7,0 (живые вакцины) & & \\
\hline $\begin{array}{c}\text { инфекция } \\
\text { (штамм «1133») }\end{array}$ & $\begin{array}{c}\text { 7,5 (инактивированные } \\
\text { вакцины) }\end{array}$ & $7,0-7,5$ & $7,60 \pm 0,20$ \\
\hline
\end{tabular}

вированных вакцин.

Также при тестировании РЭК из популяции русских белых кур в лаборатории ВНИВИП было установлено, что эти эмбрионы, в отличие от РЭК промышленных линий кур, которые не всегда дают стабильные результаты, успешно могут быть использованы в качестве диагностикумов в отношении реовирусной инфекции и инфекционного бронхита кур.

Заключение. В результате проведенных на протяжении 5 поколений исследований в популяции русских белых кур из коллекции ВНИИгРЖ доказана эффективность селекции на увеличение выхода вакцинного сырья (ААЖ) для производства вирусных вакцин. Основными критериями отбора кур при формировании гнезд являются: яйценоскость, масса яиц, средний выход ААЖ от 3-5 эмбрионов (не менее 10 мл и не менее 0,200 мл/г массы яйца). При отборе петухов в гнезда необходимо учитывать те же показатели их матерей и сестер. Селекционная работа с популяцией привела к повышению яйценоскости за 5 поколений отбора на 15\%, массы яиц - на $10 \%$. Объем ААЖ увеличился на 14\% в абсолютной величине (мл) и на $8 \%$ - в относительной, биологическая активность вируса болезни Ньюкасла (штамм «Ла-Сота») - на $11,5 \%$. Частота встречаемости кур с высоким (более 0,200 мл/г) выходом ААЖ увеличилась в среднем на 25,2\%. Результаты вирусологических исследований РЭК популяции русская белая позволяют рекомендовать их для использования в производстве ряда вирусных вакцин и диагностикумов.

Исследобания пробедены no meмe zосзадания AAAAA18-118021590129-9.

\section{Литература}

1. Muir W.M. Genome-wide assessment of worldwide chicken SNP genetic diversity indicates significant absence of rare alleles in commercial breeds / W.M. Muir, G.K. Wong, Y. Zhang et al. // PNAS. - 2008. - V. 105, No 45. - P. 
$17312-17317$

2. Гальперн И.Л., Сегал Е.Л., Федоров И.В. Проблема сохранения генетических ресурсов сельскохозяйственной птицы и возможные пути ее решения // Инновационное обеспечение яичного и мясного птицеводства России: Мат. XVIII междунар. конф. - Сергиев Посад, 2015. - С. 45-48.

3. Тяпугин Е.Е. Оценка и отбор яичных кур по показателям эм6рионального развития: автореф. дис. ... канд. биол. наук. - Дубровицы, 2013. - 22 с.

4. Соколова А.Н. Генетикоселекционные методы создания популяции кур с повышенной устойчивостью к неоплазмам: автореф. дис. ... канд. С.-х. наук. - СПб, 1999. -56 c.

5. Серова Н.Ю. Индикация и идентификация изолятов вируса инфекцион- ного бронхита кур, циркулирующих на территории Российской Федерации: автореф. дисс. .... канд. вет. наук. Cח6, 2017.-23 C.

6. Kock M. Fertile eggs - a valuable product for vaccine production / M. Kock, G. Seemonn // Lohmann Information. 2008. -V. 43, No 2. - P. 37-40.

7. Коновалова Е.Л. Технология выращивания кур, свободных от возбудителей инфекционных болезней, и их использование при диагностике вирусных заболеваний: автореф. дис. ... канд. С.-х. наук. - Троицк, 2002. - 20 C.

8. Федорова Е.С. Эффективность селекции кур породы русская белая на повышение выхода вакцинного сырья / Е.С. Федорова, О.И. Станишевская, Ю.Л. Силюкова // Генетика и разведение животных. - 2018. - № 3.- С.
46-50.

9. Лапа М.А. Критерии оценки и отбора птицы с целью повышения пищевых и биотехнологических качеств яиц: автореф. дис. ... канд. биол. наук. - СанктПетербург-Пушкин, 2015. - 23 с.

10. Митрофанова О.В. Ассоциация замены RS1 3730111 в геноме кур русской белой породы с уровнем выхода экстраэмбриональной жидкости в эмбрионах / О.В. Митрофанова, Н.В. Дементьева, Е.С. Федорова, А.П. Дысин // Аграрный вестник Урала. 2019. - №6. - C. 34-38.

\section{Для контакта с авторами:} Федорова Елена Сергеевна E-mail: osot2005@yandex.ru Станишевская Ольга Игоревна E-mail: olgastan@list.ru

\section{New Possibilities of the Preservation and Practical Usage of Rare Breeds and Populations of Poultry: The Case of Russian White Chicken Breed}

Fedorova E.S., Stanishevskaya O.I.

\section{Federal Scientific Center of Animal Husbandry of Academician L.K. Ernst}

Summary: The problem of the preservation and practical use of rare breeds and populations of poultry is reviewed on the example of Russian White chicken breed that could be used for the selection of the specialized populations of chicken as the producers of raw materials for the bioindustry. The urgency of this task is related to the problems of import substitution, adverse epizootic situation in the World's poultry production, and recent COVID-19 pandemia. The results of selection of a population of Russian White breed for higher output of the extraembryonic fluid (EEF) from 12.5-day old embryos in 5 generations are presented, with the criterion no less than $0.200 \mathrm{~mL}$ of EEF per $1 \mathrm{~g}$ of egg weight and lo less than $10 \mathrm{~mL}$ per embryo. The increase of EEF output in the selected population was also achieved via the selection for higher egg production and egg weight resulted in the increases in egg production by $15 \%$ and egg weight by $10 \%$. The absolute output ( $\mathrm{mL} / \mathrm{embryo}$ ) of EEF was increased by $14 \%$, relative output (per $1 \mathrm{~g}$ of egg weight) by 8\%; bioactivity of the Newcastle disease virus in the EEF increased by $11.5 \%$. The percentage of individuals with high EEF output was increased by $25.2 \%$ in average. The virological investigation of embryos of the selected population evidenced their suitability for the production of certain vaccines and diagnostic kits.

Key words: chicken, Russian White breed, raw materials for vaccine production, selection, extraembryonic fluid, bioactivity of viruses. 